\title{
Distribution of virulence genes and phylogenetics of uropathogenic Escherichia coli among urinary tract infection patients in Addis Ababa, Ethiopia
}

Belayneh Regasa Dadi ${ }^{*}$, Tamrat Abebe ${ }^{2}$, Lixin Zhang ${ }^{3}$, Adane Mihret ${ }^{2}$, Workeabeba Abebe ${ }^{4}$ and Wondwossen Amogne ${ }^{5}$

\begin{abstract}
Background: Urinary tract infection (UTI) is a common cause of morbidity worldwide. Uropathogenic Escherichia coli (UPEC) bacteria are the major cause of urinary tract infections. UPEC strains derive from different phylogenetic groups and possess an arsenal of virulence factors that contribute to their ability to overcome different defense mechanisms and cause disease. The objective of this study was to identify phylogroup and virulence genes of UPEC among urinary tract infection patients.

Methods: A cross sectional study was conducted from January 1, 2017 to October 9, 2017. E. coli bacteria were isolated from UTI patients using culture and conventional biochemical tests. Identification of phylogroup and genes that encodes for virulence factors was done using multiplex polymerase chain reaction (PCR). Data was processed and analyzed with SPSS version16.0 and Epi-info version 3.4.1 software.

Results: The most common urologic clinical manifestation combinations in this study were dysuria, urine urgency and urgency incontinence. The frequent UPEC virulence gene identified was fimH 164 (82\%), followed by aer 109 (54.5\%), hly 103 (51.5\%), pap 59 (29.5\%), cnf 58 (29\%), sfa 50 (25\%) and afa $24(12 \%)$.There was significant association between pap gene and urine urgency ( $p-0.016)$; sfa and dysuria and urine urgency ( $p-0.019$ and $p-0.043$ respectively); hly and suprapubic pain ( $p$-0.002); aer and suprapubic pain, flank pain and fever $(p-0.017, p-0.040, p$ 0.029 respectively). Majority of $E$. coli isolates were phylogroup B2 60(30\%) followed by D 55(27.5\%), B1 48(24\%) and A 37(18.5\%). There was significant association between E. coli phylogroup B2 and three virulence genes namely afa, pap, and sfa ( $p-0.014, p-0.002, p-0.004$ respectively).

Conclusion: In this study the most frequent $E$. coli virulence gene was fimH, followed by aer, hly, pap, cnf, sfa and afa respectively. There was significant association between $E$. coli virulence genes and clinical symptoms of UTI. The phylogenetic analysis indicates majority of uropathogenic E. coli isolates were phylogroup B2 followed by phylogroup D. Phylogroup B2 carries more virulence genes. Hence, targeting major UPEC phylogroup and virulence genes for potential vaccine candidates is essential for better management of UTI and further research has to be conducted in this area.
\end{abstract}

Keywords: Urinary tract infections, Uropathogenic Escherichia coli, Virulence genes and phylogroup

\footnotetext{
*Correspondence: belayjanimen@gmail.com

'Department of Medical Microbiology, Arba Minch University, Arba Minch,

Ethiopia

Full list of author information is available at the end of the article
}

(c) The Author(s). 2020 Open Access This article is distributed under the terms of the Creative Commons Attribution 4.0 International License (http://creativecommons.org/licenses/by/4.0/), which permits unrestricted use, distribution, and reproduction in any medium, provided you give appropriate credit to the original author(s) and the source, provide a link to the Creative Commons license, and indicate if changes were made. The Creative Commons Public Domain Dedication waiver (http://creativecommons.org/publicdomain/zero/1.0/) applies to the data made available in this article, unless otherwise stated. 


\section{Background}

Urinary tract infection (UTI) remains the most common bacterial infection in human population and is also one of the most frequently occurring nosocomial infections [1]. Its annual global incidence is of almost 250 million [2-4]. Escherichia coli is the major etiologic agent in causing UTI, which accounts for up to $90 \%$ of cases [3]. Escherichia coli strains isolated from the urinary tract are known as uropathogenic Escherichia coli [5].

Uropathogenic $E$. coli strains possess an arsenal of virulence factors that contribute to their ability to overcome different defense mechanisms cause disease. These virulence factors that are located in virulence genes include fimbriae (which help bacterial adherence and invasion), iron-acquisition systems (which allow bacterial survival in the iron-limited environment of the urinary tract), flagella and toxins (which promote bacterial dissemination).Virulence genes are located on transmissible genetic elements (plasmid) and/or on the chromosome [6] so that non-pathogenic strains acquire new virulence factors from accessory DNA [7].

Escherichia coli strains derive from different phylogenetic groups; phylogenetic typing in four groups: A, B1, B2 and D. The majority of strains responsible for extraintestinal infections, including urinary tract infections, belong to group B2 or, to a lesser degree, to group D, whereas commensal isolates belong to groups A and B1 $[8,9]$. To the best of our knowledge, there is no information on phylogenetics and genes that encode virulence factors of uropathogenic E. coli in Ethiopia. So, knowing the phylogroup and virulence factors of $E$. coli responsible for UTI is important for proper management, prevention and control of urinary tract infection.

\section{Methods}

A cross sectional study was conducted from January 1, 2017 to October 9, 2017 in selected health facilities of Addis Ababa, Ethiopia; Namely Tikur Anbessa Specialized Hospital, Yekatit 12 Hospital and Zewditu memorial Hospital. These governmental hospitals were selected because they have microbiology laboratories that perform culture and antimicrobial sensitivity testing. They are also referral hospitals so most patients from Addis Ababa visit these hospitals. Clinical data were collected using a well-designed questionnaire.

The proposal of this study was ethically approved by the Institutional Review Board (IRB) of Addis Ababa University, College of Health Sciences. Permission was obtained from Medical directors of Tikur anbessa specialized Hospital, Yekatit 12 Hospital and Zewditu Hospital. Written informed consent was obtained from each patient participated in the study. Research participants were those patients coming to Tikur Anbessa Specialized Hospital, Zewditu Memorial Hospital and Yekatit 12
Hospital that were diagnosed with urinary tract infections and gave urine sample for microbiological investigation. The study participants' age was $>1$ year old (Those children age $<1$ year were excluded from the study because it is difficult to obtain urine from these patients). Socio-demographic and clinical data were collected from the patient directly and from patient record respectively by data collectors using well designed questionnaire. Urine sample processing and microbiological investigations were conducted without delay in the Microbiology laboratory. Mid-stream urine sample was collected using sterile container from patients diagnosed with urinary tract infections. Escherichia coli isolates were presumptively identified by colonial morphology on MacConkey agar (Oxoid, UK), and further identified and confirmed by conventional biochemical tests. A sample was considered as positive for UTI if a single organism was cultured at a concentration of $\geq 10^{5} \mathrm{CFU}$ (colony forming unit) per milliliter of urine [10]. Patients having at least two of the following complaints: dysuria, urine urgency, frequency, incontinence, suprapubic pain, flank pain or costo-vertebral angle tenderness, fever $\left(\geq 38^{\circ} \mathrm{C}\right)$ and chills was considered as urinary tract infection.

In-vitro antimicrobial susceptibility testing of the bacterial isolates was performed by Kirby-Bauer disc diffusion method. The following antimicrobial agents were used with their respective concentration: trimethoprimsulfamethoxazole (SXT) $(1.25 / 23.75 \mu \mathrm{g})$, ampicillin (AMP) $(10 \mu \mathrm{g})$, nalidixic acid (NA) $(30 \mu \mathrm{g})$, amoxicillin-clavulanate (AMC) $(20 / 10 \mu \mathrm{g})$, ceftazidime (CAZ) $(30 \mu \mathrm{g})$, tetracycline (TE) $(30 \mu \mathrm{g})$, cefotaxime $(\mathrm{CTX})(30 \mu \mathrm{g})$, ceftriaxone (CRO) $(30 \mu \mathrm{g})$, gentamicin $(\mathrm{CN})(10 \mu \mathrm{g})$, ciprofloxacin $(\mathrm{CIP})(5 \mu \mathrm{g})$, amikacin (AK) $(30 \mu \mathrm{g})$, norfloxacin (NOR) $(10 \mu \mathrm{g})$, nitrofurantoin (F) $(300 \mu \mathrm{g})$, meropenem $(\mathrm{MEM})(10 \mu \mathrm{g})$, imipenem (IM) $(10 \mu \mathrm{g})$ and chloramphenicol (C) $(30 \mu \mathrm{g})$ (Oxoid, UK). The antibiotic disks were firmly placed on sterile MuellerHinton Agar (Oxoid, UK) plates previously seeded with a $24 \mathrm{~h}$ old culture of the isolate $\left(10^{6} \mathrm{CFU} / \mathrm{ml}\right.$ of $0.5 \mathrm{McFar}-$ land Standard). The plates were incubated at $37^{\circ} \mathrm{C}$ for $24 \mathrm{~h}$ and diameter of zones of inhibitions was measured using caliper and compared with the standard set by CLSI [11]. E. coli ATCC 25922 was used as reference strain. Molecular characterization of $E$. coli isolates was conducted in college of Human Medicine, Michigan State University, USA.

\section{Bacterial DNA extraction}

DNA extraction was performed using an alkaline heat lysis method. Escherichia coli strains were grown on LB medium at $37^{\circ} \mathrm{C}$ overnight. Bacteria colonies were inoculated and suspended in $1.5 \mathrm{ml}$ centrifuge tubes containing $200 \mu \mathrm{l}$ of $1 \mathrm{xPBS}$ solution, and then $800 \mu \mathrm{l}$ of $0.05 \mathrm{M}$ $\mathrm{NaOH}$ added and mixed by vortexing. The sample/mixture was incubated at $60^{\circ} \mathrm{C}$ for $45 \mathrm{~min}$. After $45 \mathrm{~min}$ $240 \mu \mathrm{l} 1 \mathrm{M}$ Tris-Cl was added to neutralize $\mathrm{NaOH}$ and 
centrifuged at 13,000 rpm for $3 \mathrm{~min}$. One thousand $\mathrm{mi}-$ croliters of the supernatant were stored at $-20^{\circ} \mathrm{C}$ as a template DNA stock $[12,13]$.

Detection of virulence genes of uropathogenic Escherichia coli The genetic determinants that are studied includes those coding for type 1 fimbriae $[\mathrm{fimH}]$, pili associated with pyelonephritis [pap], S and F1C fimbriae [sfa and foc], afimbrial adhesins $[a f a]$, hemolysin $[h l y]$, cytotoxic necrotizing factor [cnf], and aerobactin [aer] [12, 14-16].Specific primers were used to amplify sequences of the fim, pap, sfa/foc, afa, hly, chf, and aer operons. Details of primer sequences and predicted sizes of the amplified products are given in Table 1.

Detection of fim, pap and $a f a$, and $s f a / f o c$ and aer sequences were done by multiplex PCR while hly and cnf detection were done by single-plex PCR $[12,16,17]$. PCR amplification of bacterial DNA extracts was done in a total volume of $25 \mu \mathrm{l}$ containing $20 \mu \mathrm{l}$ of Platinum ${ }^{\oplus}$ PCR SuperMix (The mixture contains $\mathrm{Mg}^{++}$, dNTPs and recombinant Taq DNA polymerase at concentrations sufficient to allow amplification during PCR), $1.5 \mu \mathrm{l}$ template DNA and1.5$2 \mu \mathrm{l}(30 \mathrm{pmol}$ of each) of the primers $[12,16]$.

The amplification was carried out in a multiplex PCR $\left[\mathrm{T}_{100}{ }^{\mathrm{Tm}}\right.$ Thermal cycler (BIO RAD) \& PTC-200 Peltier Thermal cycler (MJ Research)]. Conditions consisted of an initial denaturation at $94{ }^{\circ} \mathrm{C}$ for $10 \mathrm{~min}$, followed by 30 cycles of denaturation at $94^{\circ} \mathrm{C}$ for $2 \mathrm{~min}$, annealing at a specific temperature for $30 \mathrm{~s}$ (Multiplex PCR for fimH, afa and pap annealing temperature used was $60^{\circ} \mathrm{C}$; Multiplex PCR for sfa and aer annealing temperature used was $55^{\circ} \mathrm{C}$; annealing temperature of Single-plex PCR for cnf and $h l y$ was $45^{\circ} \mathrm{C}$ and $50{ }^{\circ} \mathrm{C}$ respectively) and $72{ }^{\circ} \mathrm{C}$ for $1 \mathrm{~min}$, and final extension at $72^{\circ} \mathrm{C}$ for 10 min. A $4.5 \mu \mathrm{l}$ aliquot of the PCR product was mixed with $6 \mathrm{x}$ blue loading dye on parafilm and loaded on $1.2 \%$ agarose gel electrophoresis stained with $10 \mu \mathrm{L} 10,000 \mathrm{x}$ GelRed. Electrophoresis was carried out for $120 \mathrm{~min}$ at $110 \mathrm{~V}$ on TAE buffer system and the gel was imaged under UV light (E-gel Imager; life technologies, USA). Amplified DNA fragments of specific sizes were detected by UV-induced fluorescence and the size of the amplicons were estimated by comparing them with the $1 \mathrm{~kb}$ plus DNA ladder (Invitrogen ${ }^{\mathrm{Tx}}$ ) included on the same gel $[12,16]$.

Strain 196 was used as positive control for pap, sfa/foc, $h l y$, chf, and fimH sequences and the strain K10 was used as positive control for $a f a$. The positive control for aer was $\mathrm{J} 96$ and $\mathrm{Cl}_{1212}$ strains and distilled water is used as negative control [18-20].

\section{Phylogenetics grouping of uropathogenic Escherichia coli}

E. coli strains responsible for extra-intestinal infection are far more likely to be members of phylogroups B2 or D than $\mathrm{A}$ or $\mathrm{B} 1[7,8,21]$. This study used PCR assay to detect the genes $c h u A$ and $y j a A$, and an anonymous DNA fragment TspE4.C2 found in $E$. coli isolates to classify $E$. coli isolates into phylogroups A, B1, B2 or D [22] (See Table 2). All PCR reactions were carried out in a $25 \mu \mathrm{l}$ volume containing $20 \mu \mathrm{l}$ of $10 \mathrm{X}$ buffer (supplied with Taq polymerase), $2 \mathrm{mM}$ each $\mathrm{dNTP}, 2 \mathrm{U}$ of Taqpolymerase (Invitrogen $^{\text {TM }}$ Super mix); the amounts of primer used are $20 \mathrm{pmol}(2 \mu \mathrm{l}$ of each primers). PCR reactions (T100 Thermal cycler, BIO RAD) were performed under the following conditions: denaturation $4 \mathrm{~min}$ at $94^{\circ} \mathrm{C}, 30$ cycles of $5 \mathrm{~s}$ at $94{ }^{\circ} \mathrm{C}$ and $20 \mathrm{~s}$ at $59^{\circ} \mathrm{C}$, and a final extension step of $5 \mathrm{~min}$ at $72^{\circ} \mathrm{C}[23,24]$. Interpretation of amplified PCR products for phylogrouping E. coli was done according to Clermont et al. [22] (See Table 3).

Table 1 Primers for uropathogenic Escherichia coli virulence genes PCR assay [12, 16]

\begin{tabular}{|c|c|c|c|c|}
\hline Virulence factor & Target gene(s) & Primer Name & Primer Sequence (5'- $\left.3^{\prime}\right)$ & Size of amplicon (bp) \\
\hline \multirow[t]{2}{*}{ Type 1 fimbriae } & \multirow[t]{2}{*}{$\mathrm{fimH}$} & $\mathrm{fimH}-\mathrm{f}$ & 5'-AACAGCGATGATTTCCAGTTTGTGTG-3' & \multirow[t]{2}{*}{465} \\
\hline & & fimH-r & 5'-ATTGCGTACCAGCATTAGCAATGTCC-3' & \\
\hline \multirow[t]{2}{*}{ P fimbriae } & \multirow[t]{2}{*}{ papC } & pap1 & 5'-GACGGCTGTACTGCAGGGTGTGGCG-3' & \multirow[t]{2}{*}{328} \\
\hline & & pap2 & 5'-ATATCCTTTCTGCAGGGATGCAATA-3' & \\
\hline \multirow[t]{2}{*}{ S and FIC fimbriae } & \multirow[t]{2}{*}{$S f a / f o c D E^{h}$ region } & sfa1 & 5'-CTCCGGAGAACTGGGTGCATCTTAC-3' & \multirow[t]{2}{*}{410} \\
\hline & & sfa2 & 5'-CGGAGGAGTAATTACAAACCTGGCA-3' & \\
\hline \multirow[t]{2}{*}{ Afa adhesins } & \multirow[t]{2}{*}{$a f a C^{c}$} & afa-f & 5'-CGGCTTTTCTGCTGAACTGGCAGGC-3' & \multirow[t]{2}{*}{672} \\
\hline & & afa-r & $5^{\prime}$-CCGTCAGCCCCCACGGCAGACC-3' & \\
\hline \multirow[t]{2}{*}{ Hemolysin } & \multirow[t]{2}{*}{ hlyCA region } & hly s & 5'-AGATTCTTGGGCATGTATCCT-3' & \multirow[t]{2}{*}{556} \\
\hline & & hly as & 5'-TTGCTITGCAGACTGTAGTGT-3' & \\
\hline \multirow[t]{2}{*}{ Cytotoxic necrotizing factor } & \multirow[t]{2}{*}{ cnf } & $\operatorname{cnfs}$ & 5'-TTATATAGTCGTCAAGATGGA-3' & \multirow[t]{2}{*}{693} \\
\hline & & cnf as & 5'-CACTAAGCTITACAATATTGA-3' & \\
\hline \multirow[t]{2}{*}{ Aerobactin } & \multirow[t]{2}{*}{ incC } & aer $\mathrm{s}$ & 5'-AAACCTGGCTTACGCAACTGT-3' & \multirow[t]{2}{*}{269} \\
\hline & & aer as & 5'-ACCCGTCTGCAAATCATGGAT-3' & \\
\hline
\end{tabular}


Table 2 Primers used for phylogenetic of uropathogenic Escherichia coli [23]

\begin{tabular}{|c|c|c|c|}
\hline Primer Name & Gene Target & Nucleotide Sequence & PCR Product (bp) \\
\hline chuA.1b & chuA & 5'-ATGGTACCGGACGAACCAAC-3' & 288 \\
\hline chuA.2 & & 5'-TGCCGCCACTACCAAAGACA-3' & \\
\hline yjaA.1b & yjaA & 5'-CAAACGTGAAGTGTCAGGAG-3' & 211 \\
\hline yjaA.2b & & 5'-AATGCGTTCCTCAACCTGTG-3' & \\
\hline TspE4C2.1b & TspE4.C2 & 5'-CACTATTCGTAAGGTCATCC-3' & 152 \\
\hline TspE4C2.2b & & 5'-AGTTTATCGCTGCGGGTCGC-3' & \\
\hline AceK.f & $\operatorname{arpA}$ & 5'-AACGCTATTCGCCAGCTTGC-3' & 400 \\
\hline ArpA1.r & & 5'-TCTCCCCATACCGTACGCTA-3' & \\
\hline
\end{tabular}

\section{Data analysis}

SPSS version 16.0 and Epi-info version 3.4.1 softwares were used for data analysis. Regression and Chi-square test was performed to asses' relationship between variables. $P$ value $<0.05$ was considered as significant.

\section{Results}

Urine samples of 780 study participants who had complaints of urologic symptoms of urinary tract infections were cultured and 200 (25.6\%) Escherichia coli isolates were identified by biochemical tests. Among study participants, 265 (34\%) were males and 515 (66\%) were females.

The most common urologic clinical manifestation combinations in this study were dysuria; urine urgency and urgency incontinence followed by dysuria and urgency incontinence (see Table 4).

The antimicrobial susceptibility patterns of 200 E. coli isolates which were subjected to similar testing procedure showed that $E$. coli isolates had highest resistance (86.5\%) to ampicillin followed by ceftazidime (84\%), ceftriaxone (80.5\%), tetracycline (80\%), trimethoprim-sulfamethoxazole (68.5\%) and cefotaxime (66\%) (see Table 5).

Virulence genes were amplified and detected successfully in 198 (99\%) E. coli isolates. The most frequent $E$. coli virulence gene was fimH 164 (82\%), followed by aer 109 (54.5\%), hly 103 (51.5\%), pap 59 (29.5\%), cnf 58 (29\%), sfa 50 (25\%) and afa 24 (12\%) (see Fig. 1).

Table 3 Interpretation of amplified PCR products for phylogrouping E. coli [22]

\begin{tabular}{llll}
\hline Phylogroup & chua & yjaA & TSPEA.C2 \\
\hline A & - & - & - \\
A & - & + & - \\
B1 & - & - & + \\
B1 & - & + & + \\
B2 & + & + & + \\
B2 & + & + & - \\
D & + & - & - \\
D & + & - & + \\
\hline
\end{tabular}

The virulence genes fimH (456 bp), afa (672 bp), pap (328 bp), sfa (410 bp), aer (269 bp), cnf (693 bp) and hly (556 bp) were successfully amplified. One kilobase plus (1 kb plus) DNA ladder was used to determine the base pair size (see Fig. 2).

There was significant association between pap gene and urine urgency ( $p$-0.016); sfa and dysuria and urine urgency ( $p-0.019$ and $p-0.043$ respectively); $h l y$ and suprapubic pain $(p-0.002)$; aer and suprapubic pain, flank pain and fever $(p-0.017, p-0.040, p-0.029$ respectively) (see Table 6).

\section{Phylogenetics of uropathogenic Escherichia coli}

The distribution of phylogenetic groups amongst Escherichia coli isolates was determined by the following genes; $\operatorname{arp} A$ (400 bp), chu $A$ (288 bp), yja $A$ (211 bp) and an anonymous DNA fragment that is found in E. coli worldwide; TspE4C2 (152 bp). One kilobase plus (1 kb plus) DNA ladder was used to determine the base pair size (see Fig. 3).

Phylogenetic analysis indicates majority of uropathogenic Escherichia coli isolates were group B2 60(30\%) followed by group D 55(27.5\%), group B1 48(24\%) and group A 37(18.5\%) (see Fig. 4).

In this study there was significant association between Escherichia coli phylogroup B2 and three virulence genes namely afa, pap, and $s f a(p-0.014, p-0.002, p-0.004$ respectively). Similarly, there was significant association between

Table 4 Common combinations of clinical manifestations

\begin{tabular}{ll}
\hline Clinical data combinations & Frequency \\
\hline Dysuria, urine urgency, urgency incontinence & 176 \\
Dysuria, urgency incontinence & 100 \\
Dysuria, urine urgency, flank pain & 80 \\
Dysuria, urine urgency & 78 \\
Dysuria, urgency incontinence, suprapubic pain & 60 \\
Urine urgency, urgency incontinence & 54 \\
Dysuria, suprapubic pain, flank pain & 50 \\
Dysuria, suprapubic pain & 42 \\
\hline
\end{tabular}


Table 5 Antimicrobial susceptibility patterns of $E$. coli isolates

\begin{tabular}{llll}
\hline Antimicrobial agents & Number of resistance (\%) & Number of intermediate (\%) & Number of susceptible (\%) \\
\hline Ciprofloxacin & $29(14.5)$ & 0 & $171(85.5)$ \\
Norfloxacin & $30(15)$ & 0 & $170(85)$ \\
Nitrofurantoin & $10(5)$ & 0 & $190(95)$ \\
Trimethoprim-sulfamethoxazole & $137(68.5)$ & 0 & $63(31.5)$ \\
Tetracycline & $160(80)$ & 0 & $40(20)$ \\
Ceftriaxone & $161(80.5)$ & $9(4.5)$ & $30(15)$ \\
Ampicillin & $173(86.5)$ & $6(3)$ & $21(10.5)$ \\
Nalidixic acid & $42(21)$ & 0 & $158(79)$ \\
Amoxicillin-clavulanate & $58(29)$ & $36(18)$ & $106(53)$ \\
Ceftazidime & $168(84)$ & $19(9.5)$ & $13(6.5)$ \\
Cefotaxime & $132(66)$ & $2(1)$ & $66(33)$ \\
Amikacin & $5(2.5)$ & 0 & $195(97.5)$ \\
Meropenem & 0 & 0 & $200(100)$ \\
Imipenem & 0 & 0 & $200(100)$ \\
Chloramphenicol & $33(16.5)$ & 0 & $167(83.5)$ \\
Gentamicin & $40(20)$ & 0 & $160(80)$
\end{tabular}

Escherichia coli phylogroup D and two virulence genes namely fimH and pap ( $p-0.043, p-0.019$ respectively). There was significant association between Escherichia coli phylogroup A and virulence genes fimH and afa ( $p$ $0.011, p-0.002$ respectively). Phylogroup B1 has significant association with pap gene $(p-0.001)$. The virulence factor that encodes pap gene has significant association with Escherichia coli phylogroup B2, D and B1 ( $p-0.002$, $p$-0.019, $p$-0.001 respectively) (see Table 7).

\section{Discussion}

In this study higher proportion of urinary tract infections in females (66\%) than in males $(34 \%)$ were observed. UTI is more common in females than in males because structurally the female urethra is less effective in preventing the bacterial entry for colonization i.e. the urethra is shorter and wider. Escherichia coli is common because it is a normal flora in large intestine and can easily be acquired via faecal contamination with urinary tract especially in female it causes ascending UTI [25]. The highest incidence of urinary tract infections was observed in the age groups $26-45$. This could be due to the fact that this age group is sexually active. Sexual intercourse may access entry of bacteria in to bladder. Identification of virulence factors that are encoded by uropathogenic E. coli are important for pathogenesis, severity of urinary tract infection, targets for vaccine and drug development [26].

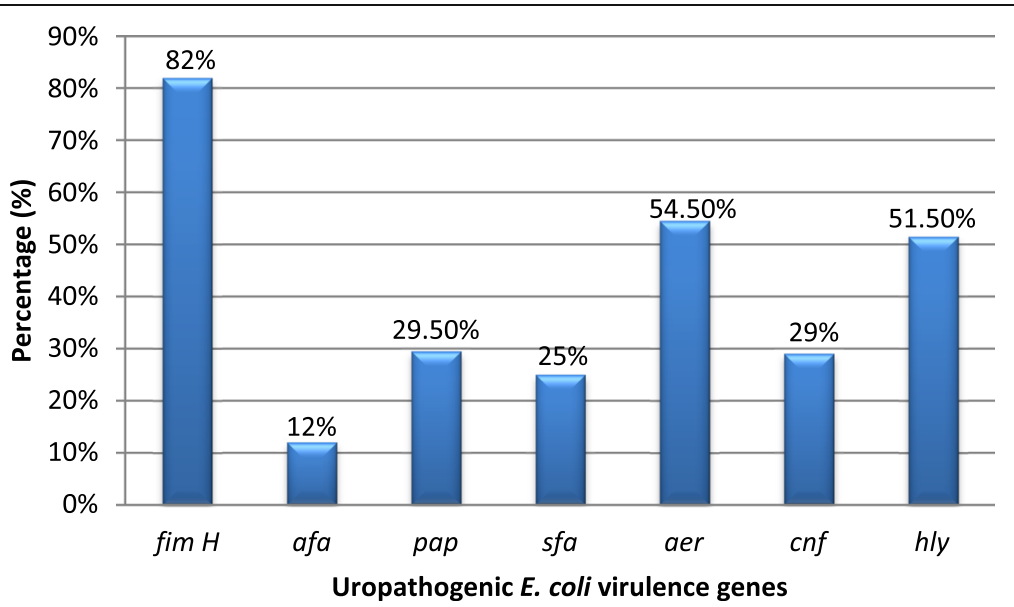

Fig. 1 Virulence genes of uropathogenic Escherichia coli. (Proportion of uropathogenic E. coli virulence genes. The most frequent virulence gene was fim $H$, followed by aer, hly, pap, cnf, sfa and afa) 


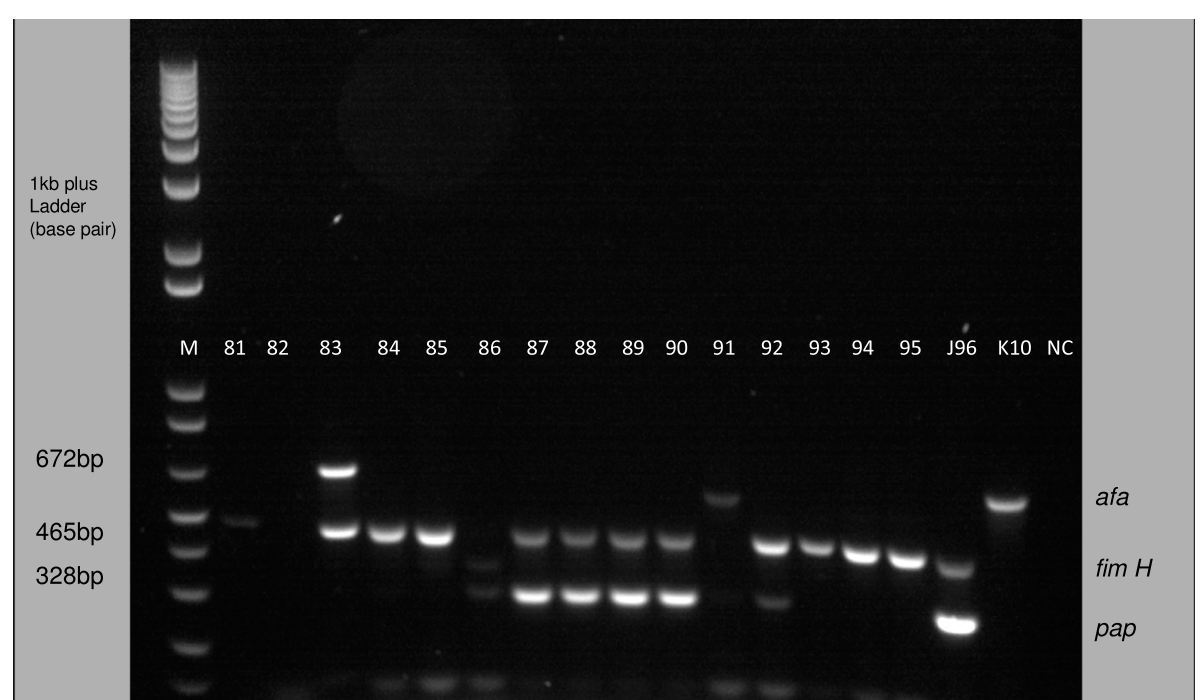

Fig. 2 Representative 1.2\% agarose gel electrophoresis of uropathogenic Escherichia coli virulence genes isolated from urinary tract infection patients. (Lane M, 1-kb plus ladder; lane 1-15, amplified E. coli PCR products (sample 81-95) with the following virulence genes, pap (328 bp), fimH (456 bp) and afa (672 bp); lane 16, strain J96 positive control; lane 17, strain K10 positive control and lane 20, distilled water as negative control)

In our study fimH adhesion gene was the most common and present in 164 (82\%) uropathogenic E. coli isolates which is in agreement with studies conducted in Romania, 86\% [16]; Mongolia, 89.9\% [27], Iran, 86.17\% [28], 79.67\% [29] and China, 87.4\% [30]. Targeting fimH as vaccine candidate is important for prevention of UTI and currently vaccine targeting fim $H$ as potential vaccine candidate is under investigation. Antibodies against fimH prevent colonization of urinary tract by UPEC isolates [26].In this study, we found no significant association between fimH gene and clinical symptoms of UTI $(p>$ 0.05 ), but this does not mean fimH is not involved in pathogenesis of UTI.

Pyelonephritis associated pili (pap) gene was found in 59 (29.5\%) uropathogenic E. coli isolates which is comparable to study conducted in Iran, 30.2\% [6]; Mexico, 24.7\% [31]; Romania, 36\% [16] and Brazil, 32\% [32]; but lower than studies conducted in Iran, 50.4\% [28], 57\% [33] and Egypt 54\% [34]. In this study, there was significant association between presence of pap gene and urine urgency $(p-0.016)$, which was commonly observed clinical symptom in most UTI patients. This indicates that UPEC uses pap genes as virulence factor to cause UTIs.

$\mathrm{S}$ and F1C fimbriae (sfa gene) was found in $50(25 \%)$ uropathogenic E. coli isolates which is similar to studies conducted in Pakistan, 27\% [35]; Romania, 23\% [16]; Tunisia, 34\% [12]; Iran, 32\% [36] and Iraq, 22.7\% [37]; but lower than studies conducted in Denmark, 46\% [38]; Iran, 81\% [33] and South Korea, 100\% [39] and higher than studies conducted in Mongolia, 8.8\% [27] and China, 8\% [30]. In our study, there was significant association between presence of $s f a$ gene, and dysuria and urine urgency ( $p-0.019$ and $p-0.043$ respectively). This indicates that sfa genes are important for pathogenesis of UPEC to cause UTI and responsible for clinical symptoms of UTIs.

Afa adhesin (afa gene) was found in 24 (12\%) uropathogenic $E$. coli isolates which is similar to studies conducted in Iran, 12\% [33]; Mexico, 12.8\% [31]; Brazil, $11 \%$ [32] and Romania, 14\% [16]. Afimbrial adhesins (afa) may favor establishment of chronic and/or recurrent urinary tract infections [40]. In this study, we found no significant association between afa gene and clinical symptoms of UTI $(p>0.05)$.

Uropathogenic E. coli secretes toxins like $\alpha$-haemolysin $(h l y A)$ and cytotoxic necrotizing factor 1 (cnfl). Hly Alpha promotes bladder cell exfoliation and cell lysis, which facilitates iron and nutrient acquisition by the bacteria. Cnflinvolved in bladder cell exfoliation and increased levels of bacterial internalization [26, 41].

In this study 103 (51.5\%) uropathogenic E. coli isolates carries hemolysin (hly) gene which is comparable to studies conducted in Iran, 50.4\% [28] and South Korea, 62\% [39]; but higher than studies conducted in Zimbabwe, 12.5\% [14]; Tunisia, 19\% [12]; Poland, 18.5\% [42]; Mexico, 15.4\% [31] and China, 11.6\% [30].In our study, hemolysin gene was significantly associated with suprapubic pain $(p-0.002)$. This indicates that hemolysin may be responsible for clinical manifestation in UTI patients. Alpha-hemolysin encoded by $h l y A$ is an extracellular cytolytic protein toxin that is produced by up to $50 \%$ of UPEC isolates. Alpha-hemolysin has been associated with clinical severity in UTI patients [43]. Currently vaccine against $h l y A$ that protect renal damage is under investigation [44]. 


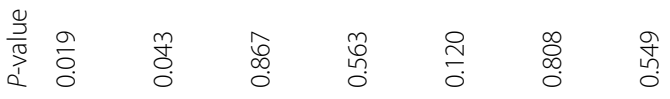

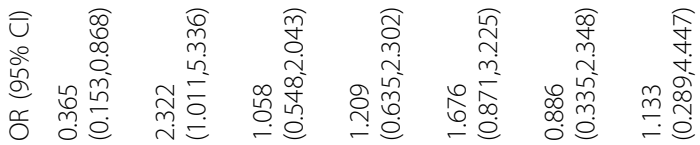

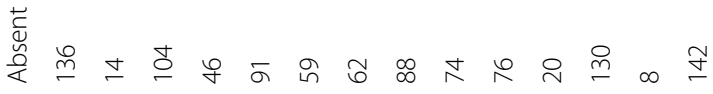

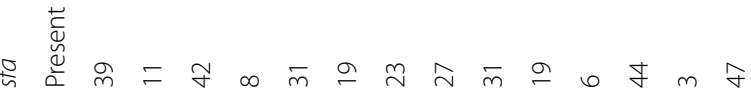

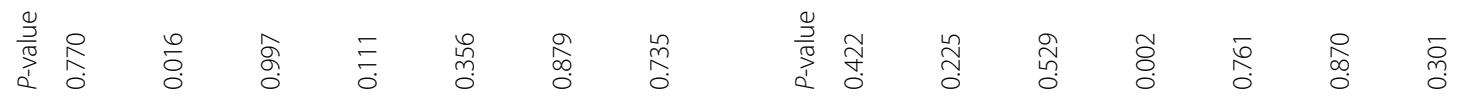

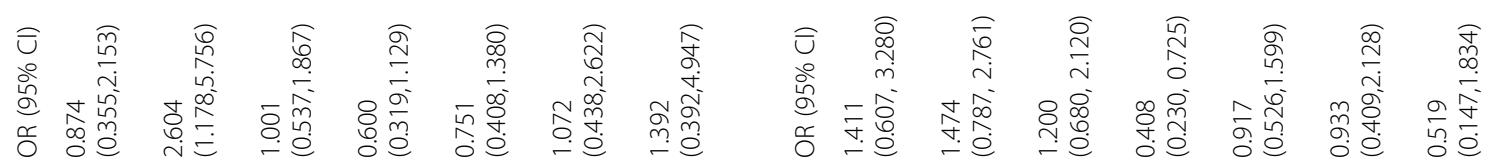

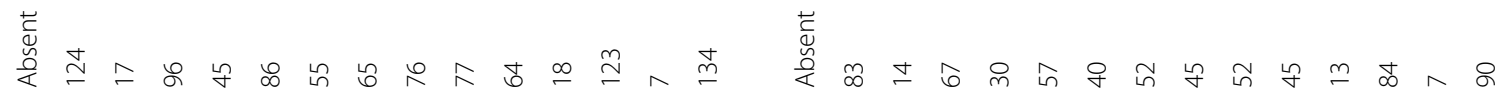

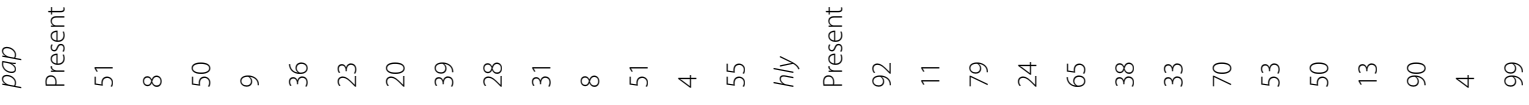

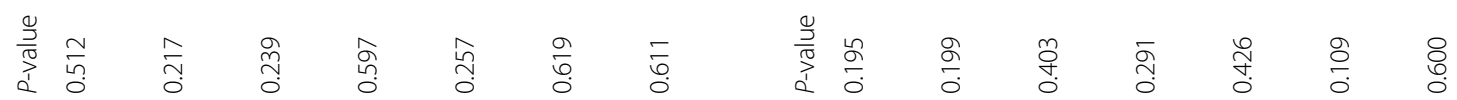

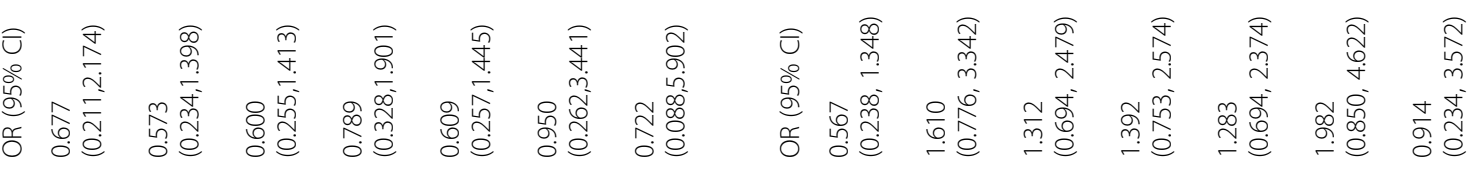

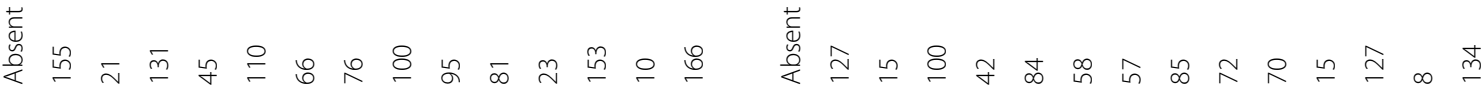
蒂

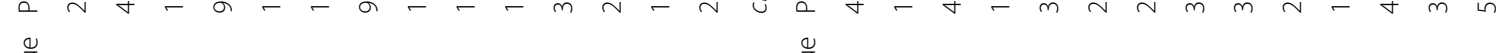

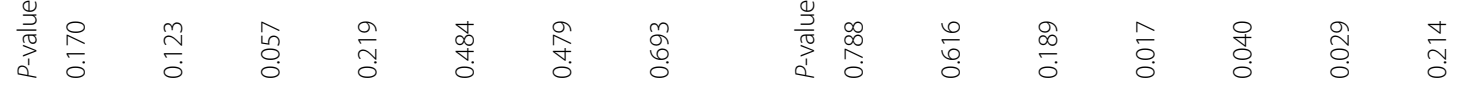

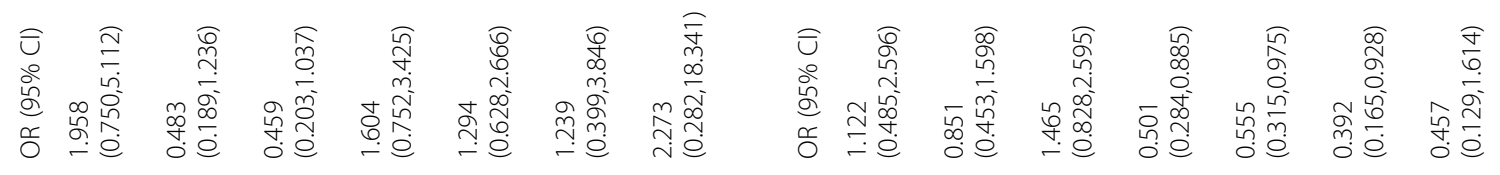
峜

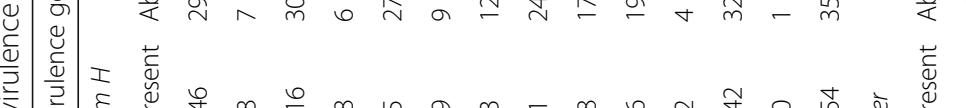

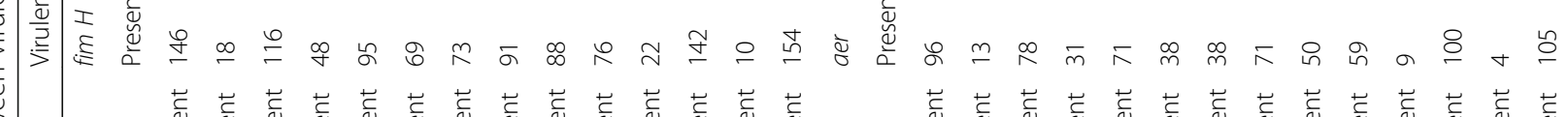

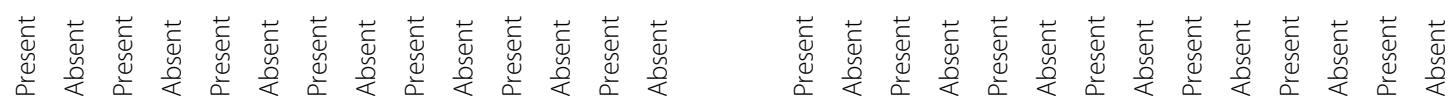

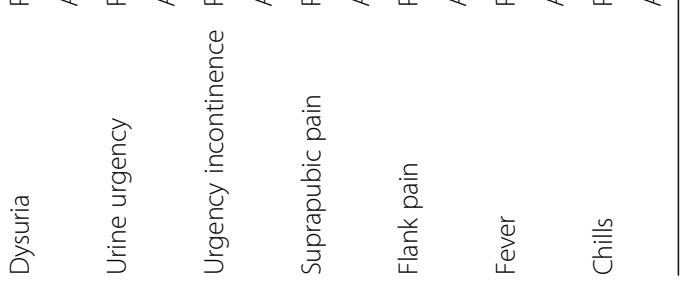




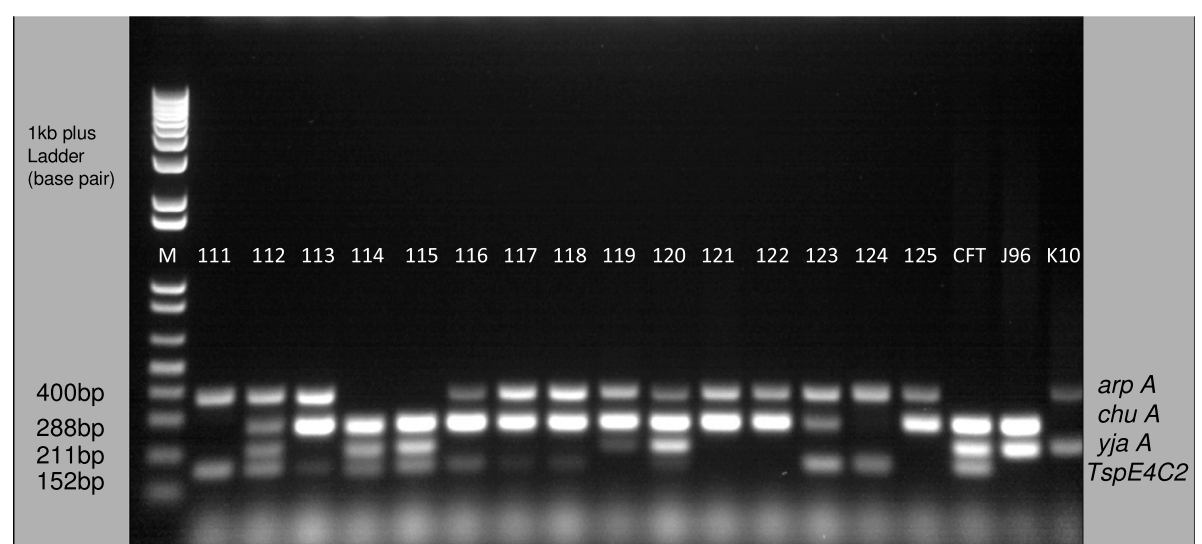

Fig. 3 Representative 1.2\% agarose gel electrophoresis of uropathogenic Escherichia coli genes used to classify Escherichia coli into different phylogroup. (Lane M, 1-kb plus ladder; lane 1-15, amplified PCR products (sample 111-125) with the following Escherichia coli phylogrouping genes; arp A (400 bp), chu A (288 bp), yja A (211 bp) and TspE4C2 (152 bp); lane 16, strain CFT073 positive control; lane 17, strain J96 positive control and lane 20, strain K10 positive control)

In our study we found 58 (29\%) uropathogenic E. coli isolates carries cytotoxic necrotizing factor 1 (cnfl) which is similar to studies conducted in Iran, 36.5\% [45] and Pakistan, 20\% [35]; but higher than studies conducted in Tunisia, 3\% [12]; Romania, 13\% [16] and Poland, 12.1\% [42]. In this study, we found no significant association between $c n f 1$ gene and clinical symptoms of UTI $(p>0.05)$.

Iron is generally required for bacterial growth during infection. Thus UPEC stains uses iron acquisition genes like aerobactin, aer [46]. In this study we found 109 (54.5\%) uropathogenic E. coli isolates carries aerobactin

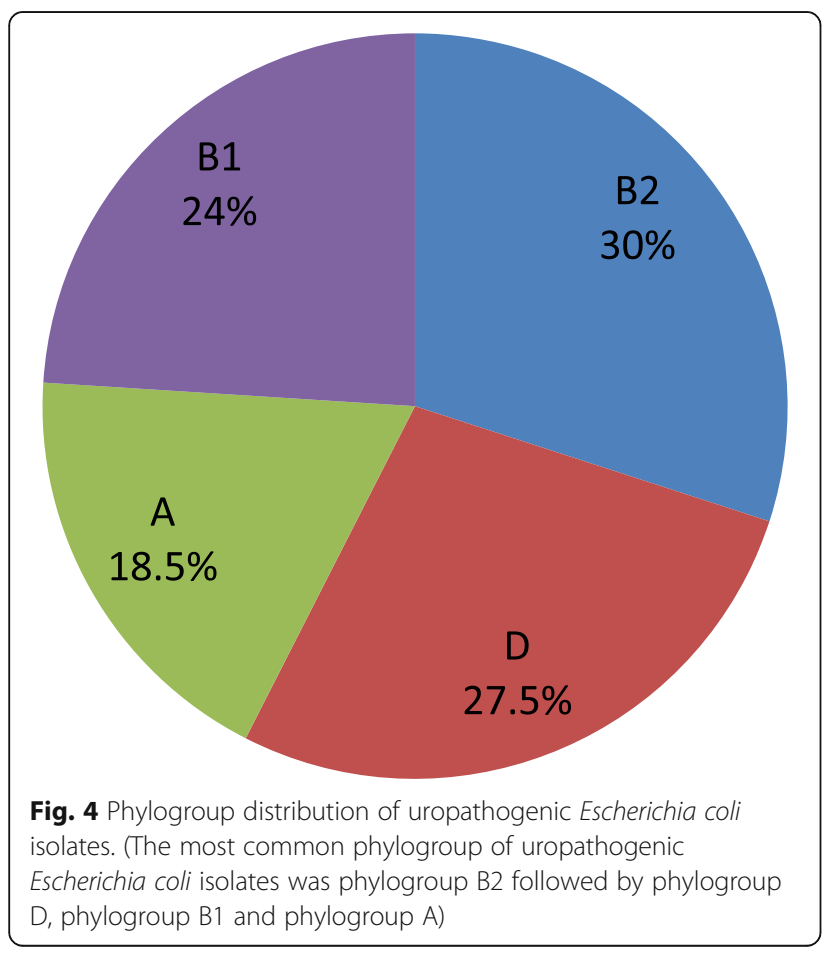

(aer) genes which is similar to studies conducted in Romania, 54\% [16]; Tunisia, 52\% [12]; Egypt, 51\% [34] and Poland, 52.6\% [42]; but lower than studies conducted in South Korea, 81\% [39] and Iran, 73.1\% [45]. Currently, Siderophore proteins are under investigation for potential vaccine candidate against UTI [26].There was significant association between aer gene and suprapubic pain, flank pain and fever $(p-0.017, p-0.040, p-0.029$ respectively). Thus, the high prevalence of aer gene in our study may be due to UPEC utilizes aerobactin virulence gene as a means of acquisition of iron and associated with clinical features of suprapubic pain, flank pain and fever which were observed in most UTI patients.

From clinical point of view UTI is classified as upper (proximal) urinary tract infection and lower (distal) urinary tract infection. Upper urinary tract infection includes pyelonephritis while lower urinary tract infection includes cystitis and urethritis. The common clinical symptom of upper urinary includes flank pain, fever, chills and costovertebral angle tenderness. The common clinical symptom of lower urinary includes dysuria and frequency. The above mentioned clinical symptoms of UTI that is correlated with virulence genes should be interpreted in this aspect.

The difference in virulence genes prevalence between our study and different studies abroad may be due to sample size difference and methodology difference. Several virulence determinants are the product of different genes, which can be detected by PCR method [16, 28, 42, 45]. However, when there is mutation at the level of the corresponding gene, this will lead to negative PCR. Thus negative PCR doesn't mean absence of specific virulence gene [12].

Phylogenetic analyses have shown that virulent uropathogenic E. coli strains belonged typically to group B2 and less often to group D [38, 39]. Our finding is in 


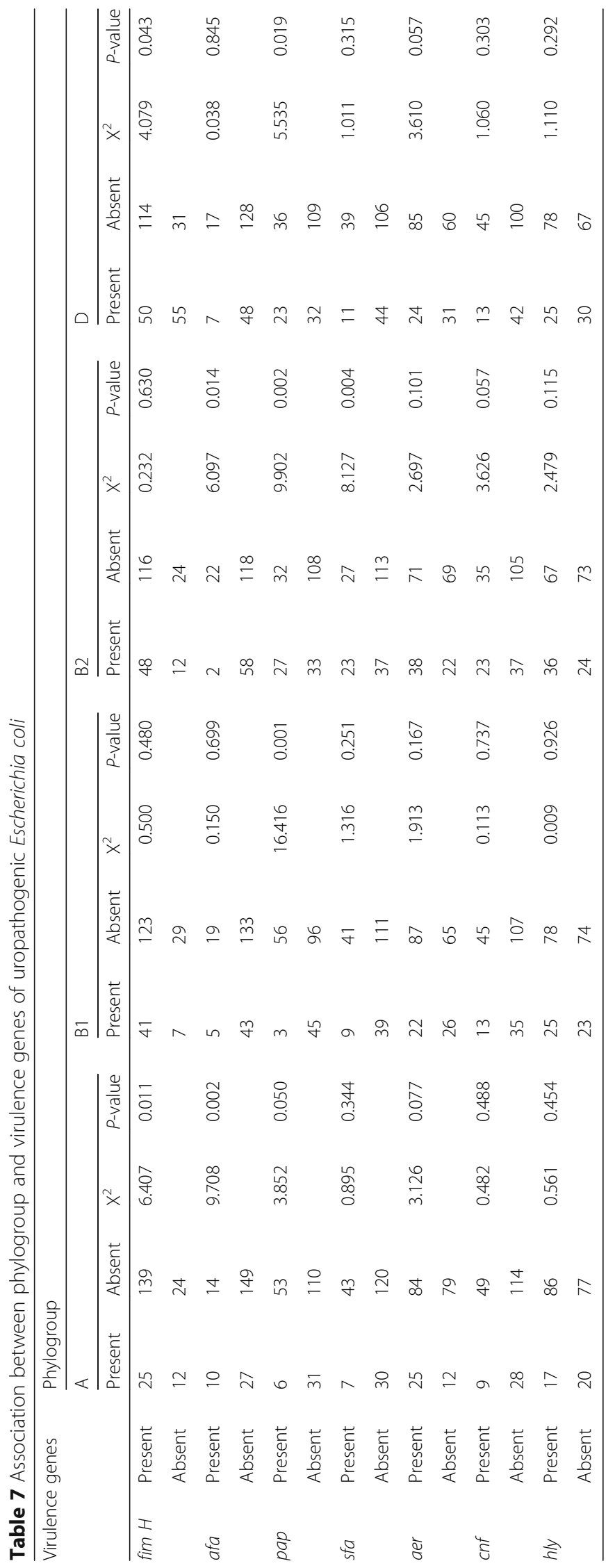


agreement with studies conducted in Denmark [38], Pakistan [35], South Korea [39], Poland [42] and Mexico [31] where it was found that the majority of isolates of E. coli predominantly belong to phylogenetic group B2. These findings are indicative of virulent strains of UPEC are common in study area among UTI patients and measures needs to be taken to combat these virulence strains through designing and implementing appropriate prevention and control strategies.

In our study the phylogenetic analysis indicated majority of uropathogenic E. coli isolates were group B2 60(30\%) followed by group D 55(27.5\%), group B1 48(24\%) and group A $37(18.5 \%)$ which is in agreement with study conducted by Munkhdelger et al [27], where B2 (33.8\%) was dominant strains followed by D (28.4\%) strains, A (19.6\%) strains and B1 (18.2\%) strains. Similar study conducted by Kot et al [42], showed that $38.1 \%$ E. coli strains belonged to phylogenetic group B2, $35.3 \%$ to group D, $18.5 \%$ to group A, and $8.1 \%$ to group B1. Phylogenetic group A, represented $18 \%$ of isolates, which was higher than in studies conducted in South Korea 3.44\% [39] and Iran $0.7 \%$ [47], but some studies found phylogroup A was the dominant phylogroup $[9,15,48]$ suggesting that the colon may be the main reservoir for strains that cause urinary tract infections [9]. In some studies, phylogroup D was the dominant strain $[25,49]$. These different prevalence of the phylogenetic groups may be due to health status of the host, and geographic conditions, or variations in methodology and sample size [50].

In our study there was significant association between E. coli phylogroup B2 and three virulence genes namely $a f a, p a p$, and $s f a(p-0.014, p-0.002, p-0.004$ respectively). This finding is explained by the fact that $E$. coli strains belonging to phylogroup B2 contained a greater number of virulence genes than $E$. coli than other phylogroup as reported by other studies on UPEC isolates [38, 51]. There was also significant association between $E$. coli phylogroup D and two virulence genes namely fim $H$ and pap ( $p$-0.043, $p-0.019$ respectively) which is in agreement with a study conducted in Thailand [25].

In this study high prevalence of drug resistance to ceftazidime (84\%), ceftriaxone (80.5\%), and cefotaxime (66\%) was observed [52]. Resistance to ceftriaxone was observed in $80.5 \%$ of UPEC isolates, which is comparable to studies conducted in Nigeria 86\% [13], India 81.8\% [53] and China $84.8 \%$ [30], but higher than studies conducted in Nigeria 23.3\% [54] and Mexico 10.2\% [21]. Resistance to cefotaxime was observed in $66 \%$ of UPEC isolates, which is in agreement with studies conducted in Nigeria $68 \%$ [13], India 66.66\% [55] and Iraq 78\% [37], but higher than studies conducted in Ethiopia 18.7\% [56], Nigeria 4.4\% [9] and South Korea 7.8\% [43]. Ceftriaxone is recommended for treatment of severe pyelonephritis in Ethiopia by national standard treatment guidelines [57]. Resistance to ceftriaxone could be due to transmission of resistant strains/isolates among hospitalized patients and noncompliance with medication. To reduce the incidence of resistance, empirical antibiotic selection in treatment of UTI must be based on the knowledge of local prevalence of causative uropathogens and their respective antimicrobial sensitivities rather than on universal guidelines [58].

\section{Limitations of the study}

The triplex PCR phylogroup assignment used in this study has limitations like many strains could be potentially misassigned as this method has low sensitivity and expected to fail in allocating recombinant variants. Exclusion of infants $<1$ years and not differentiating nosocomial and community acquired infections are the limitation of this study. Whole Genome Sequencing, Pulse Field Gel Electrophoresis and MLVA were not done.

\section{Conclusions}

In our study the most frequent uropathogenic E. coli virulence gene was fimH, followed by aer, hly, pap, cnf, $s f a$ and $a f a$ respectively. The most common urologic clinical manifestation combinations in this study were dysuria, urine urgency and urgency incontinence. There was significant association between pap gene and urine urgency; sfa and dysuria and urine urgency; hly and suprapubic pain; aer and suprapubic pain, flank pain and fever. The phylogenetic analysis indicates majority of uropathogenic $E$. coli isolates were phylogroup B2 followed by phylogroup D. There was significant association between $E$. coli phylogroup B2 and three virulence genes namely afa, pap, and sfa. Hence, targeting major uropathogenic Escherichia coli phylogroup and virulence genes for potential vaccine candidates is essential for better management of UTI and further research has to be conducted in this area.

\section{Abbreviations \\ aer: aerobactin; afa: afimbrial adhesins; bp: base pair; CFU: Colony forming unit; CLSI: Clinical and Laboratory Standards Institute; Cnf: cytotoxic necrotizing factor; DNA: Deoxyribonucleic acid; dNTPs: deoxynucleoside triphosphates; fimH: type1 fimbriae; hly: hemolysin; IRB: Institutional Review Board; $\mathrm{NaOH}$ : Sodium Hydroxide; pap: pili associated with pyelonephritis; PCR: Polymerase chain reaction; sfa: S and F1C fimbriae; UPEC: uropathogenic E. coli; UTI: Urinary tract infection}

\section{Acknowledgments \\ The authors would like to thank those who were involved in this research. The authors also thank Arba Minch University, Addis Ababa University and} Michigan State University for their support throughout the research process.

\section{Authors' contributions}

BR carried out proposal development, data collection, data analysis and drafted the manuscript. TA and LZ participated in proposal development, data collection, provided resources for data collection and participated in manuscript writing. AM, WAm and WAb participated in proposal development and provided input in manuscript writing. All authors read and approved the final manuscript. 


\section{Funding}

This research was supported by Arba Minch University, Addis Ababa University and Michigan State University. The funding agencies had no involvement in the design of the study, data collection and analysis, interpretation of data and writing the manuscript.

\section{Availability of data and materials}

The datasets generated and/or analyzed during the current study are not publicly available due to ethical and confidentiality reasons but are available from the corresponding author on reasonable request under the Ethics Committee's approval.

\section{Ethics approval and consent to participate}

The proposal of this study was ethically approved by the Institutional Review Board (IRB) of Addis Ababa University, College of Health Sciences. Permission was obtained from Medical directors of Tikur anbessa specialized Hospital, Yekatit 12 Hospital and Zewditu Hospital. Written informed consent was obtained from each patient participated in the study. The study participants' age was $>1$ year old. Before starting data collection, the purpose of the study was explained to all study participants and written informed consent was obtained. For age group 1-16years old written consent was obtained from the parents or guardians.

\section{Consent for publication}

Not applicable.

\section{Competing interests}

The authors declare that they have no competing interests.

\section{Author details}

'Department of Medical Microbiology, Arba Minch University, Arba Minch, Ethiopia. ${ }^{2}$ Department of Microbiology, Immunology and Parasitology, Addis Ababa University, Addis Ababa, Ethiopia. ${ }^{3}$ Department of Epidemiology and Biostatistics, Michigan State University, East Lansing, USA. ${ }^{4}$ Department of Pediatrics, Addis Ababa University, Addis Ababa, Ethiopia. ${ }^{5}$ Department of Internal Medicine, Addis Ababa University, Addis Ababa, Ethiopia.

Received: 16 April 2019 Accepted: 3 February 2020

Published online: 07 February 2020

\section{References}

1. Gastmeir P, Kampf G, Wischnewski N, Hauer T, Schulgen G, Schumacher M, et al. Prevalence of nosocomial infections in representative German hospitals. J Hosp Infect. 1998;38:37-49.

2. Ronald AR, Nicolle LE, Stamm E, Krieger J, Warren J, Schaeffer A, et al. Urinary tract infection in adults: research priorities and strategies. Int J Antimicrob Agents. 2001;17(4):343-8.

3. Loh KY, Sivalingam N. Urinary tract infections in pregnancy. Malaysian Fam Physician. 2007;2:54-7.

4. Griebling TL. Urologic diseases in American project: trends in resource use for urinary tract infections in women. J Urology. 2005;173(4):1281-7.

5. Schwartz DJ, Kalas V, Pinkner JS, Chen SL, Spaulding CN, Dodson KW, et al. Positively selected FimH residues enhance virulence during urinary tract infection by altering FimH conformation. Proc Natl Acad Sci U S A. 2013; 110(39):15530-7.

6. Farshad S, Ranjbar R, Japoni A, Hosseini M, Anvarinejad M, Mohammadzadegan R. Microbial susceptibility, virulence factors, and plasmid profiles of uropathogenic Escherichia coli strains isolated from children in Jahrom, Iran. Arch Iran Med. 2012;15(5):312-6.

7. Johnson JR, Kuskowski MA, Obryan T, Colodner R, Raz R. Virulence genotype and phylogenetic origin in relation to antibiotic resistance profile among Escherichia coli urine sample isolates from Israeli women with acute uncomplicated cystitis. Antimicrob Agents Chemother. 2006;49:26-31.

8. Horcajada JP, Soto S, Gajewski A, Smithson A, Jiménez de Anta MT, Mensa J, et al. Quinolone-resistant uropathogenic Escherichia coli strains from phylogenetic group B2 have fewer virulence factors than their susceptible counterparts. J Clin Microbiol. 2005:43:2962-4.

9. Romanus II, Eze AT. Antibiotics susceptibility patterns and clonal relatedness of uropathogenic Escherichia coli in Abakaliki, Ebonyi state. Canad J Pure Appl Sci. 2011;5(2):1475-9.
10. Farmer JJ. Enterobacteriaceae: introduction and identification. In: Murray PR, Baron EJ, Pfaller MA, Tenover FC, Yolken RH, editors. Manual Clin Microbiol. Washington, D.C: ASM Press; 1999. p. 442-50.

11. CLSI. Performance Standards for Antimicrobial Susceptibility Testing. Clinical and Laboratory Standards Institute, Twenty-seventh Information Supplement, 2017; 37(1), M100-S26:1-249.

12. Tarchouna M, Asma A, Ben-Selma W, Boukadida J. Distribution of uropathogenic virulence genes in Escherichia coli isolated from patients with urinary tract infection. Inter J Infect Dis. 2013;17:e450-3.

13. Abiodun $\mathrm{AO}$, Olufunke OA, Dunah FC, Oladiran F. Phenotypic identification and phylogenetic characterization of Uropathogenic Escherichia coli in symptomatic pregnant women with urinary tract infections in SouthWestern Nigeria. Int J Biol. 2014;6(4):145-55.

14. Mbanga J, Mudzana R. Virulence factors and antibiotic resistance patterns of uropathogenic Escherichia coli. Afr J Microbiol Res. 2014;8(43):3678-86. https://doi.org/10.5897/AJMR2014.7034.

15. Derakhshandeh A, Firouzi R, Motamedifar M, Arabshahi S, Novinrooz A, Boroojeni AM, et al. Virulence characteristics and antibiotic resistance patterns among various phylogenetic groups of Uropathogenic Escherichia coli isolates. Jpn J Infect Dis. 2015;68:428-31.

16. Usein CR, Damian M, Tatu-Chitoiu D, Capusa C, Fagaras R, Tudorache D, et al, Prevalence of virulence genes in Escherichia coli strains isolated from Romanian adult urinary tract infection cases. J Cell Mol Med. 2001;5(3):303-10.

17. Le Bouguénec C, Archambaud M, Labigne A. Rapid and specific detection of the pap, afa, and sfa adhesins - encoding operons in uropathogenic Escherichia coli strains by polymerase chain reaction. J Clin Microbiol. 1992; 30(5):1189-93.

18. Johnson JR, Stell AL. Extended virulence genotypes of Escherichia coli strains from patients with urosepsis in relation to phylogeny and host compromise. J Infect Dis. 2000;181(1):261-72.

19. Le Bougue'nec C, Lalioui L, Du Merle L, Jouve M, courcoux P, Bouzari S, et al. Characterization of AfaE adhesins produced by extraintestinal and intestinal human Escherichia coli isolates. PCR assays for detection of Afa adhesions that do or do not recognize Dr blood group antigens. J Clin Microbiol 2001; 39:1738-1745.

20. Bindereif A, Neilands JB. Promoter mapping and transcriptional regulation of the iron assimilation system of plasmid ColV-K30 in Escherichia coli K-12. J Bacteriol. 1985:162:1039-46.

21. Molina-López J, Aparicio-Ozores G, Ribas-Aparicio RM, Gavilanes-Parra S, Chávez-Berrocal ME, Hernández-Castro R, et al. Drug resistance, serotypes, and phylogenetic groups among uropathogenic Escherichia coli including O25-ST131 in Mexico City. J Infect Dev Ctries. 2011;5(12):840-9.

22. Clermont $\mathrm{O}$, Bonacorsis BE. Rapid and simple determination of Escherichia coli phylogenetic group. Appl Environ Microbiol. 2000;66:4555-8.

23. Clermont O, Christenson JK, Denamur E, Gordon DM. The Clermont Escherichia coli phylo-typing method revisited: improvement of specificity and detection of new phylo-groups. Environ Microbiol Rep. 2013;5(1):58-65.

24. Alm EW, Walk ST, Gordon DM. The niche of Escherichia coli. In: Walk ST, Feng PCH, editors. Population genetics of Bacteria. Washington, DC: ASM Press; 2011. p. 107-23.

25. Themphachana M, Kongpheng S, Rattanachuay P, Khianngam S, Singkhamanan K, Sukhumungoon P. Molecular characterization of virulence and antimicrobial susceptibility profiles of uropathogenic Escherichia coli from patients in a tertiary hospital, southern Thailand. Southeast Asian J Trop Med Public Health. 2016;46(6):1021-30.

26. Flores-Mireles AL, Walker JN, Caparon M, Hultgren SJ. Urinary tract infections: epidemiology, mechanisms of infection and treatment options. Nat Rev Microbiol. 2015;13:269-84.

27. Munkhdelger Y, Gunregjav N, Dorjpurev A, Juniichiro N, Sarantuya J. Detection of virulence genes, phylogenetic group and antibiotic resistance of uropathogenic Escherichia coli in Mongolia. J Infect Dev Ctries. 2017;11(1):51-7.

28. Momtaz H, Karimian A, Madani M, Safarpoor Dehkordi F, Ranjbar R, Sarshar $M$, et al. Uropathogenic Escherichia coli in Iran: serogroup distributions, virulence factors and antimicrobial resistance properties. Ann Clin Microbiol Antimicrob. 2013;12:8.

29. Karimian A, Momtaz H, Mahbobe MM. Detection of uropathogenic Escherichia coli virulence factors in patients with urinary tract infections in Iran. Afr J Microbiol Res. 2012;6(39):6811-6.

30. Wang Y, Zhao S, Han L, Guo X, Chen M, Ni Y, et al. Drug resistance and virulence of uropathogenic Escherichia coli from Shanghai, China. J Antibiot. 2014;67:799-805. 
31. Paniagua-Contreras GL, Monroy-Pe'rez E, Rodrı'guez-Moctezuma JR, Domı́nguez-Trejo P, Vaca-Paniagua F, Vaca S. Virulence factors, antibiotic resistance phenotypes and O-serogroups of Escherichia coli strains isolated from community-acquired urinary tract infection patients in Mexico. J Microbiol Immunol Infect 2015; 1-8. doi: https://doi.org/10. 1016/j.jmii.2015.08.005

32. Santo E, Macedo C, Marin JM. Virulence factors of uropathogenic Escherichia coli from a University Hospital in Ribeirão Preto, São Paulo, Brazil. Rev Inst Med trop S Paulo. 2006;48(4):185-8.

33. Rahdar M, Rashki A, Miri HR, Ghalehnoo MR. Detection of pap, sfa, afa, foc, and fim Adhesin-encoding operons in Uropathogenic Escherichia coli isolates collected from patients with urinary tract infection. Jundishapur J Microbiol. 2015;8(8):e22647.

34. Alabsi MS, Ghazal A, Sabry SA, Alasaly MM. Association of some virulence genes with antibiotic resistance among uropathogenic Escherichia coli isolated from urinary tract infection patients in Alexandria, Egypt: A hospitalbased study. J Glob Antimicrob Resist. 2014;2:83-6.

35. Bashir S, Haque A, Sawar Y, Ali A, Anwar MI. Virulence profile of different phylogenetic groups of locally isolated community acquired uropathogenic E. coli from Faisalabad region of Pakistan. Ann Clin Microbiol Antimicrob. 2012;11:23. https://doi.org/10.1186/1476-0711-11-23.

36. Jalali HR, Eslami G, Fallah F, Pourbakhsh A. Genotyping of virulence factors of Uropathogenic Escherichia coli by PCR. NovelBiomed. 2015;3(4):177-81.

37. Merza NS, Jubrael JMS. The prevalence of virulence factors among Uropathogenic Escherichia coli strains isolated from different hospitals in Kurdistan region-Iraq. Int J Bioinform Biomed Eng. 2015;1(3):338-43.

38. Ejrnæs K, Stegger M, Reisner A, Ferry S, Monsen T, Stig EH, et al. Characteristics of Escherichia coli causing persistence or relapse of urinary tract infections: phylogenetic groups, virulence factors and biofilm formation. Virulence. 2011;2(6):528-37. https://doi.org/10.4161/viru.2.6.18189.

39. Lee JH, Subhadra B, Son YJ, Kim DH, Park HS, Kim JM, et al. Phylogenetic group distributions, virulence factors and antimicrobial resistance properties of uropathogenic Escherichia coli strains isolated from patients with urinary tract infections in South Korea. Lett Appl Microbiol. 2016;62:84-90.

40. Bien J, Sokolova O, Bozko P. Role of Uropathogenic Escherichia coli virulence factors in development of urinary tract infection and kidney damage. Int J Nephrol. 2012:1-15. https://doi.org/10.1155/2012/681473.

41. Garcia TA, Ventura CL, Smith MA, Merrell DS, O'Brien AD. Cytotoxic necrotizing factor 1 and hemolysin from uropathogenic Escherichia coli elicit different host responses in the murine bladder. Infect Immun. 2013;81:99-109.

42. Kot B, Wicha J, Gruzewska A, Piechota M, Wolska K, Obrebska M. Virulence factors, biofilm-forming ability, and antimicrobial resistance of urinary Escherichia coli strains isolated from hospitalized patients. Turk J Med Sci. 2016;46:1908-14.

43. Yun KW, Kim HY, Park HK, Kim W, Lim IS. Virulence factors of uropathogenic Escherichia coli of urinary tract infections and asymptomatic bacteriuria in children. J Microbiol Immun Infect. 2014;47:455-61.

44. Sivick KE, Mobley HL. Waging war against uropathogenic Escherichia coli: winning back the urinary tract. Infect Immun. 2010;78:568-85.

45. Tabasi M, Karam MRA, Habibi M, Mostafavi E, Bouzari S. Genotypic characterization of virulence factors in Escherichia coli isolated from patients with acute cystitis, pyelonephritis and asymptomatic Bacteriuria. J Clin Diagn Res. 2016;10(12):DC01-7.

46. Garenaux A, Caza M, Dozoise CM. The ins and out of siderophore mediated uptake by extra-intestinal pathogenic Escherichia coli. Vet Microbiol. 2011; 153:89-98.

47. Iranpour D, Hassanpour M, Ansari H, Tajbakhsh S, Khamisipour G, Najafi A. Phylogenetic groups of Escherichia coli strains from patients with urinary tract infection in Iran based on the new Clermont Phylotyping method. Biomed Res Int. 2015:1-7. https://doi.org/10.1155/2015/846219.

48. Grude N, Potaturkina-Nesterova NI, Jenkins A, Strand L, Nowrouzian FL, Nyhus J, et al. A comparison of phylogenetic group, virulence factors and antibiotic resistance in Russian and Norwegian isolates of Escherichia coli from urinary tract infection. Clin Microbiol Infect. 2007;13:208-11.

49. Gao Q, Zhang D, Ye Z, Zhu X, Yang W, Dong L, et al. Virulence traits and pathogenicity of uropathogenic Escherichia coli isolates with common and uncommon O serotypes. Microb Pathog. 2017;104:217e224.

50. Derakhshandeh A, Firouzi R, Moatamedifar M, Motamedi A, Bahadori M, Naziri Z. Phylogenetic analysis of Escherichia coli strains isolated from human samples. Mol Biol Res Commun. 2013;2(4):143-9.
51. Johnson JR, Kuskowski MA, Gajewski A, Soto S, Horcajada JP, Jimenez de Anta MT, et al. Extended virulence genotypes and phylogenetic background of Escherichia coli isolates from patients with cystitis, pyelonephritis or prostatitis. J Infect Dis. 2005;191:46-50; PMID:15593002. https://doi.org/10. 1086/426450

52. Regasa Dadi B, Abebe T, Zhang L, Mihret A, Abebe W, Amogne W. Drug resistance and plasmid profile of uropathogenic Escherichia coli among urinary tract infection patients in Addis Abeba. J Infect Dev Ctries. 2018;12: 608-15. https://doi.org/10.3855/jidc.9916.

53. Anusha SU, Sundar SK, Rajan S. RAPD pattern, virulence nature and plasmid profile of MDR uropathogenic Escherichia coli. Adv Appl Sci Res. 2015;6(7):145-51

54. Akingbade O, Balogun S, Ojo D, Akinduti P, Okerentugba PO, Nwanze JC, et al. Resistant plasmid profile analysis of multidrug resistant Escherichia coli isolated from urinary tract infections in Abeokuta, Nigeria. Afr Health Sci. 2014;14(4):821-8.

55. Annapurna YV, Reddy BS, Lakshmi W. Multidrug resistance and virulence phenotypes among Uropathogenic Escherichia coli. Int J Curr Microbiol App Sci. 2014;3(6):222-9.

56. Gizachew $M$, Kebede $M$, Merid $Y$, Sinshaw $Y$, Tiruneh $M$, Alemayehu $M$, et al. Escherichia coli isolated from patients suspected for urinary tract infections in Hawassa referral hospital, southern Ethiopia: an institution based cross sectional study. E3 J Microbiol Res. 2013;1(1):009-15.

57. FMHACA. Standard Treatment Guidelines For General Hospital. Food, Medicine and Healthcare Administration and Control Authority of Ethiopia, 3rd Edn, pp. 2014; 233-7.

58. Abdu A, Kachallah M, Bolus DY. Antibiotic susceptibility patterns of Uropathogenic Escherichia coli among patients with urinary tract infections in a tertiary care hospital in Maiduguri, north eastern, Nigeria. J Biosci Biotechnol Discov. 2018;3:14-24.

\section{Publisher's Note}

Springer Nature remains neutral with regard to jurisdictional claims in published maps and institutional affiliations.

Ready to submit your research? Choose BMC and benefit from

- fast, convenient online submission

- thorough peer review by experienced researchers in your field

- rapid publication on acceptance

- support for research data, including large and complex data types

- gold Open Access which fosters wider collaboration and increased citations

- maximum visibility for your research: over $100 \mathrm{M}$ website views per year

At BMC, research is always in progress.

Learn more biomedcentral.com/submissions 